\title{
2-Heptylcyclopropane-1-Carboxylic Acid Disperses and Inhibits Bacterial Biofilms
}

\section{OPEN ACCESS}

Edited by:

Rustam Aminov,

University of Aberdeen,

United Kingdom

Reviewed by:

Diane McDougald,

University of Technology Sydney,

Australia

Wolf-Rainer Abraham,

Helmholtz Center for Infection

Research, Helmholtz Association of German Research Centers (HZ),

Germany

Shi-qi An,

University of Southampton, United Kingdom

*Correspondence:

Jessica Amber Jennings

jjnnings@memphis.edu

${ }^{\dagger}$ These authors have contributed equally to this work and share first authorship

Specialty section: This article was submitted to Antimicrobials, Resistance and Chemotherapy,

a section of the journal

Frontiers in Microbiology

Received: 22 December 2020

Accepted: 29 April 2021

Published: 09 June 2021

Citation:

Harrison ZL, Awais R, Harris M, Raji B, Hoffman BC, Baker DL and Jennings JA (2021)

2-Heptylcyclopropane-1-Carboxylic Acid Disperses and Inhibits Bacterial Biofilms. Front. Microbiol. 12:645180.

doi: 10.3389/fmicb.2021.645180

\section{Zoe L. Harrison ${ }^{1 \dagger}$, Rukhsana Awais ${ }^{1+}$, Michael Harris ${ }^{1}$, Babatunde Raji ${ }^{2}$, Brian C. Hoffman ${ }^{2}$, Daniel L. Baker ${ }^{2}$ and Jessica Amber Jennings ${ }^{1 *}$}

${ }^{1}$ Department of Biomedical Engineering, University of Memphis, Memphis, TN, United States, ${ }^{2}$ Department of Chemistry, University of Memphis, Memphis, TN, United States

Fatty-acid signaling molecules can inhibit biofilm formation, signal dispersal events, and revert dormant cells within biofilms to a metabolically active state. We synthesized 2heptylcyclopropane-1-carboxylic acid (2CP), an analog of cis-2-decenoic acid (C2DA), which contains a cyclopropanated bond that may lock the signaling factor in an active state and prevent isomerization to its least active trans-configuration (T2DA). 2CP was compared to C2DA and T2DA for ability to disperse biofilms formed by Staphylococcus aureus and Pseudomonas aeruginosa. 2CP at $125 \mu \mathrm{g} / \mathrm{ml}$ dispersed approximately $100 \%$ of S. aureus cells compared to 25\% for C2DA; both 2CP and C2DA had significantly less $S$. aureus biofilm remaining compared to T2DA, which achieved no significant dispersal. 2CP at $125 \mu \mathrm{g} / \mathrm{ml}$ dispersed approximately $60 \%$ of $P$. aeruginosa biofilms, whereas C2DA and T2DA at the same concentration dispersed $40 \%$. When combined with antibiotics tobramycin, tetracycline, or levofloxacin, 2CP decreased the minimum concentration required for biofilm inhibition and eradication, demonstrating synergistic and additive responses for certain combinations. Furthermore, 2CP supported fibroblast viability above $80 \%$ for concentrations below $1 \mathrm{mg} / \mathrm{ml}$. This study demonstrates that 2CP shows similar or improved efficacy in biofilm dispersion, inhibition, and eradication compared to C2DA and T2DA and thus may be promising for use in preventing infection for healthcare applications.

Keywords: biofilm, dispersal, Staphylococcus aureus, Pseudomonas aeruginosa, diffusible signaling factors, 2decenoic acid, anti-biofilm agents

\section{INTRODUCTION}

A biofilm is an aggregate of microbial cells that attaches to various surfaces, including tissue and medical implants (Stoodley et al., 2013; Saeed et al., 2019). Almost 80\% of human infections are caused by the development of biofilms by pathogenic bacterial strains such as Staphylococcus aureus, Staphylococcus epidermis, Pseudomonas aeruginosa, and Escherichia coli (Brady et al., 2006). The attachment of these and other bacterial strains to implant or tissue surfaces to form biofilms poses a particular risk for recurring infections, as the cells within a biofilm are resistant to both antibiotics and immune cell clearance (Bauer and Grosso, 2013). The recalcitrance of biofilms to treatment is multifactorial, owing in part to secretion of exopolymeric substances (EPS) and 
alteration of the bacterial metabolic state (Flemming et al., 2016). EPS secretion enhances bacterial attachment, resistance to mechanical stresses, and facilitation of nutrient transport and may limit diffusion of antimicrobials and immune cell penetration (Molin and Tolker-Nielsen, 2003; Czaczyk and Myszka, 2007; Flemming, 2016). Immobilized subgroups of bacterial cells within the biofilm have decreased metabolic activity and can increase the minimum inhibitory concentration of antibiotics up to 1,000 times higher for biofilms compared to planktonic bacteria (Keren et al., 2004). These and other complexities associated with biofilm infections have led to extensive research of their mechanism of action and potential novel treatments.

Although current clinical treatments for biofilm infections typically include debridement of infected tissue and prescription of high-dose systemic antibiotics, there are a number of nonantibiotic methods currently being studied for their potential to prevent and treat biofilms. Some of these therapies include natural-derived molecules targeting specific aspects of the biofilm life cycle. Enzymes such as glycoside hydrolases and proteases disperse biofilm bacteria by degrading the EPS (Jennings et al., 2015). Antimicrobial peptides (AMPs) typically have cationic amphipathic structures that can disrupt bacterial cell membranes to inhibit biofilms (Batoni et al., 2016). Hydrophobic D-amino acids are secreted by bacteria prior to dispersal of biofilms and have been shown to inhibit biofilm growth in vitro and in vivo, although their mechanism of action remains unclear (Hochbaum et al., 2011). Some types of bacteria also secrete biosurfactant molecules called rhamnolipids (Nickzad and Déziel, 2014), which inhibit bacterial attachment to surfaces and trigger degradation of the EPS during dispersal. Sugar alcohols like mannitol and erythritol have been shown to stimulate metabolism of bacteria that causes awakening of dormant cells and increased susceptibility to antibiotics (Pace et al., 2019). AMPs and the sugar alcohol mannitol have been shown to eradicate both $P$. aeruginosa and $S$. aureus infections when combined with typical concentrations of antibiotics (Barraud et al., 2013; Dosler and Karaaslan, 2014; de Breij et al., 2016; Pace et al., 2019), although neither of these methods have been attempted clinically.

A class of medium-chain fatty-acid molecules has been shown to induce dispersion of preformed biofilms and inhibit biofilm formation (Davies and Marques, 2009; Ryan and Dow, 2011; Jennings et al., 2012). These specific medium-chain fatty acids are members of a family of diffusible signal factors (DSF) in bacteria. DSF are secreted by bacteria to function in cell-cell communication or quorum sensing (Solano et al., 2014). One well-studied DSF molecule is cis-2-decenoic acid (C2DA), which is released by $P$. aeruginosa and has been shown to inhibit biofilm formation and to disperse established biofilms of multiple strains (Davies and Marques, 2009). However, other studies have shown difficulty in reproducing these results, with less than $10 \%$ dispersion of $S$. aureus and Acinetobacter baumannii strains at $400 \mu \mathrm{M}$ concentration ( $\mathrm{Su}$ et al., 2011). It has been observed that some of these fatty-acid signaling factors revert dormant bacterial cells to a metabolically active state (Marques et al., 2014), which in combination with antimicrobials could decrease bacterial viability (Allison et al., 2011; Rahmani-Badi et al., 2014;
Masters et al., 2016; Saeed et al., 2019). Moreover, these compounds have cross-kingdom efficacy in that they have been shown to inhibit and disperse biofilms formed by multiple types of microorganisms, including gram-positive bacteria, gramnegative bacteria, and fungi (Wang et al., 2004). C2DA was also shown to inhibit $S$. aureus growth at a concentration of 500 $\mu \mathrm{g} / \mathrm{ml}$ and to prevent biofilm formation at a concentration of $125 \mu \mathrm{g} / \mathrm{ml}$, with neither concentration showing cytotoxic effects in fibroblasts (Jennings et al., 2012). Dispersal and inhibition effects may be mediated by activation of gene pathways that control motility, metabolism, and persistence (Amari et al., 2013; Rahmani-Badi et al., 2015b). While mechanisms of action remain unclear (Jennings et al., 2012), recent work shows that the cisconformation of this molecule increases membrane permeability and could allow for entry of more small-molecule antibiotics into the cells as compared to the less active trans-isomer (Masters et al., 2016).

Activity of DSF molecules appears to be dependent on the conformation of atoms around the point of unsaturation at carbon 2. cis-Alkenes may isomerize to trans- when exposed to light, elevated temperature, or radiation (Dugave and Demange, 2003). These conditions, one or more of which may be used in the fabrication and/or sterilization of medical devices or therapeutics, can lead to isomerization of the alkene portion of the fattyacid DSF (Tipnis and Burgess, 2018). In this study, we have developed chemical routes for synthesis of a cyclopropanated analog, 2-heptylcyclopropane-1-carboxylic acid (2CP), that locks this molecule into a cis-like configuration. This configuration eliminates the potential for cis/trans-isomerization and oxidative degradation that is possible for C2DA when exposed to light, heat, and radiation. We evaluated the hypothesis that $2 \mathrm{CP}$ disperses and inhibits biofilm using in vitro assays of $S$. aureus and $P$. aeruginosa biofilm dispersion. These were chosen as representative specimens as $S$. aureus is a major pathogen in bone infection, and $P$. aeruginosa is prevalent in soft tissue infection; both strains selected for this study are clinically derived. We further evaluated the combination of $2 \mathrm{CP}$ with antibiotics to identify synergistic and additive responses through minimum biofilm inhibitory concentration (MBIC) and minimum biofilm eradication concentration (MBEC) assays compared to C2DA and T2DA. We compared compatibility with mammalian cells at concentrations active against biofilms for all three 2-decenoic acid analogs and compared preliminary stability of 2CP to C2DA in an accelerated ultraviolet light-driven degradation scenario.

\section{MATERIALS AND METHODS}

\section{Synthesis of C2DA and 2CP}

A common synthetic approach using a single starting material was used to generate C2DA via Jones oxidation and then Lindlar reduction, and 2CP via Lindlar reduction, Simmons-Smith cyclopropanation, and finally Jones oxidation (Supplementary Figure 1). ${ }^{1} \mathrm{HNMR}$ was performed to determine whether $2 \mathrm{CP}$ had been synthesized with a "cis-like" conformation (Supplementary Figures 2, 3). T2DA was purchased from Cayman Chemical and was used without purification. 


\section{Dispersion}

Dispersion assays were performed to compare the dispersion activity of each analog against 7-day biofilms. 2CP (stabilized version of C2DA) was compared with C2DA (active, positive control) and T2DA (inactive/active, negative control). Each well of a 96-well plate was seeded with $150 \mu \mathrm{l}$ of bacterial culture (S. aureus, UAMS-1, or P. aeruginosa, PA-ATCC 27317) and incubated for 7 days at $37^{\circ} \mathrm{C}$ to result in biofilms. Media [Tryptic Soy Broth (TSB)] was changed after careful aspiration every $24 \mathrm{~h}$. On day 7, each well was again carefully aspirated and then received $195 \mu \mathrm{l}$ of TSB and $5 \mu \mathrm{l}$ of fatty-acid stock ranging in concentration from 0 to $500 \mu \mathrm{g} / \mathrm{ml}$. Fattyacid concentrations were made in absolute ethanol; thus, the final ethanol concentration in wells was $2.5 \%$. The plates were incubated for $24 \mathrm{~h}$ at $37^{\circ} \mathrm{C}$, then turbidity was measured at $540 \mathrm{~nm}$. Turbidity readings were performed using a Biotek Synergy $^{\mathrm{TM}}$ H1 microplate reader, with increased turbidity readings indicating a higher number of viable bacterial cells. Afterward, the media was aspirated and the plate was washed three times using phosphate-buffered saline (PBS). The relative percentage of attached cells as compared to non-treated controls were measured using BacTiter-Glo ${ }^{\text {TM }}$ (Promega) Luciferase assay for ATP production, with higher percentages indicating a higher quantity of attached biofilm cells.

\section{Inhibition}

Synergy assays were performed to determine the effects of 2CP when used in combination with various antimicrobials against gram-positive $S$. aureus and gram-negative $P$. aeruginosa. Tobramycin (MP Biomedicals, Irvine, CA, United States), tetracycline (MP Biomedicals, Irvine, CA, United States), and levofloxacin (Alfa Aesar, Tewksbury, MA, United States) were chosen for evaluation based on prior work, demonstrating their synergistic effects with C2DA (Masters et al., 2016). A checkerboard assay was prepared in 96-well plates with increasing antibiotic concentration on the horizontal axis and increasing 2CP concentration on the vertical axis. Tested concentrations of 2CP, C2DA, and T2DA ranged from 0 to 4,000 $\mu \mathrm{g} / \mathrm{ml}$. Antibiotic concentrations tested ranged from 0 to 2,500 $\mu \mathrm{g} / \mathrm{ml}$. Each plate was then inoculated with $S$. aureus (UAMS1) or $P$. aeruginosa (PA-ATCC 27317) overnight growths for a final dilution of 1 in 50 or 1 in 200, respectively, and incubated overnight. Inhibition was defined as a lack of visible growth after a 24-h incubation period.

The fractional inhibitory concentration index (FICI) was used to determine synergistic, additive, or antagonistic responses between the three antibiotics and three fatty acids. To calculate the FICI, the MIC of the antibiotic when combined with fatty acids was divided by the MIC of the antibiotic alone and added to the MIC of fatty acid when combined with antibiotics and divided by the MIC of fatty acid when applied alone (Equation 1). FICI values less than or equal to 0.5 indicate synergy, values between 0.5 and 1 indicate additivity, values between 1 and 2 indicate indifference, and values above 2 indicate antagonism (Equation 1) (European Committee for Antimicrobial Susceptibility Testing (EUCAST) of the European Society of Clinical Microbiology and
Infectious Dieases (ESCMID), 2000).

$$
F I C I=\frac{M I C_{A B X(C)}}{M I C_{A B X(S)}}+\frac{M I C_{F A(C)}}{M I C_{F A(S)}}
$$

Equation 1. FICI calculation using the concentrations of antibiotics (ABX) and fatty acids (FA) alone (S) and in combination (C).

\section{Eradication}

Bacteria (S. aureus, UAMS-1, or P. aeruginosa, PA-ATCC 27317) were grown overnight in TSB by incubation at $37^{\circ} \mathrm{C}$. One milliliter of bacterial solution was diluted in $9 \mathrm{ml}$ of TSB. An amount of $150 \mu \mathrm{l}$ of the bacterial stock solution was seeded into each well of a 96-well $\mathrm{MBEC}^{\mathrm{TM}}$ Biofilm Inoculator plate, followed by overnight incubation at $37^{\circ} \mathrm{C}$ to form the biofilm. The next day, the medium from each well was carefully aspirated, allowing the biofilm to remain both on the pegs of the top plate and the bottom of the wells. Stocks of tobramycin, tetracycline, and levofloxacin as well as varying concentrations of C2DA, T2DA, and $2 \mathrm{CP}$ were added to the wells. Tested concentrations of $2 \mathrm{CP}$, $\mathrm{C} 2 \mathrm{DA}$, and T2DA ranged from 0 to $4,000 \mu \mathrm{g} / \mathrm{ml}$. Antibiotic concentrations tested ranged from 0 to $2,500 \mu \mathrm{g} / \mathrm{ml}$. These plates were incubated at $37^{\circ} \mathrm{C}$ for $24 \mathrm{~h}$. The next day, the pegged lids were removed and added to new plates containing $150 \mu \mathrm{l}$ of sterile TSB in each well. Plates were sonicated for $5 \mathrm{~min}$ at $40 \mathrm{kHz}$ (Fisher Scientific Ultrasonic Bath, 9.5 l) to remove the viable bacteria attached to the peg surface and then incubated for $24 \mathrm{~h}$. Turbidity was measured by reading absorbance at $540 \mathrm{~nm}$ for bacterial growth in the presence of fixed concentrations of the antibiotics with varying concentrations of $2 \mathrm{CP}, \mathrm{C} 2 \mathrm{DA}$, and T2DA. MBECs were determined by the lowest concentration that had no turbid growth after treatment and sonication.

The fractional biofilm eradication concentration (FBEC) index was used to determine synergistic, additive, or antagonistic responses between the three antibiotics and three fatty acids. The FBEC index was determined in an identical method to the FICI: the MBEC of the antibiotic when combined with fatty acids was divided by the MBEC of the antibiotic alone and added to the MBEC of fatty acid when combined with antibiotics and divided by the MBEC of fatty acid when applied alone (Equation 2). FBEC index values less than or equal to 0.5 indicate synergy, values between 0.5 and 1 indicate additivity, values between 1 and 2 indicate indifference, and values above 2 indicate antagonism.

$$
F B E C=\frac{M B E C_{A B X(C)}}{M B E C_{A B X(S)}}+\frac{M B E C_{F A(C)}}{M B E C_{F A(S)}}
$$

Equation 2. FBEC index calculation using the concentrations of antibiotics (ABX) and fatty acids (FA) alone (S) and in combination (C).

\section{Cytocompatibility}

NIH-3T3 fibroblasts were seeded $\left(1 \times 10^{4}\right.$ cells $\left./ \mathrm{cm}^{2}\right)$ in 24well plates in Dulbecco's modified Eagle's medium (DMEM) supplemented with $10 \%$ fetal bovine serum and $100 \mu \mathrm{g} / \mathrm{ml}$ Normocin (Invivogen, San Diego, CA, United States) for $24 \mathrm{~h}$ at $37^{\circ} \mathrm{C}$ and $5 \% \mathrm{CO}_{2} .2 \mathrm{CP}, \mathrm{C} 2 \mathrm{DA}$, and $\mathrm{T} 2 \mathrm{DA}$ were added in 
varying concentrations from 0 to $1,000 \mu \mathrm{g} / \mathrm{ml}$ in ethanol for a final ethanol concentration of $2.5 \%$. Controls with no ethanol addition were also used to normalize percentage viability. Plates were incubated for $24 \mathrm{~h}$, after which cell viability was measured using CellTiter-Glo ${ }^{\circledR}$ (Promega, Madison, WI, United States).

\section{Stability of C2DA and 2CP}

Oxidative degradation and isomerization of C2DA and 2CP were assessed using negative-ion LC-MS to quantify the loss of each parent DSF following exposure to the photoinitiator Irgacure 2959 (Sigma-Aldrich, St. Louis, MO, United States). Aqueous solutions (10 $\mathrm{ml}$ total volume, $10 \%$ final methanol concentration) of C2DA and 2CP (200 ng/ $\mu \mathrm{l})$ were prepared from methanolic stocks. Irgacure was also prepared as a methanolic stock with final concentrations varying from $0,0.05$, and $0.1 \%(\mathrm{w} / \mathrm{v})$. Solutions of $\mathrm{C} 2 \mathrm{DA}$ or $2 \mathrm{CP}$ with and without the initiator were then exposed to UV at $365 \mathrm{~nm}$ for up to $4 \mathrm{~h}$ using a Spectrolinker XL-1500 UV crosslinker (Westbury, NY, United States). Triplicate samples $(200 \mu \mathrm{l})$ were taken at timepoints between 0 and $240 \mathrm{~min}$ and were extracted by the method of Bligh and Dyer. The chloroform extracts were then dried and resuspended in $4 \mathrm{ml}$ of HPLCgrade water. Samples $(10 \mu \mathrm{l})$ were analyzed via negative-ion LC-ESI-MS, using a Thermo Fisher Hypersil BDS C18 column and an isocratic mobile phase of 55: $45(\mathrm{v} / \mathrm{v})$ methanol: aqueous ammonium hydroxide $(10 \mu \mathrm{M})$. Peak areas for molecular anions of C2DA and 2CP were quantified using calibration curves using decanoic acid as an internal standard. The concentration of each sample was calculated, and the change in concentration of $2 \mathrm{CP}$ and C2DA over time was tracked.

\section{Statistical Analysis}

Statistical analysis was performed using SigmaPlot (Systat Software Inc., San Jose, CA, United States) and GraphPad Prism 7.2 software (GraphPad Software Incorporation, La Jolla, CA, United States). Data was assessed first by performing the Shapiro-Wilk normality test, followed by the Brown-Forsythe equal variance test. If both passed, data was further analyzed with one-way analysis of variance (ANOVA) followed by HolmSidak post-hoc analysis to detect significant between experimental groups $(\alpha=0.05)$. If normality and equal variance were not passed, data was analyzed using Kruskal-Wallis ANOVA on ranks, followed by the Tukey post-hoc test.

\section{RESULTS}

\section{Dispersion}

2CP at $125 \mu \mathrm{g} / \mathrm{ml}$ dispersed approximately 100\% of S. aureus biofilms grown for $24 \mathrm{~h}$, compared to wells treated with C2DA which had $75 \%$ of biofilm remaining compared to untreated controls; T2DA-treated biofilms did not show any dispersion at this concentration. At concentrations of $62.5 \mu \mathrm{g} / \mathrm{ml}$ and above, both 2CP and $\mathrm{C} 2 \mathrm{DA}$ had significantly less $S$. aureus biofilm remaining in wells compared to wells treated with T2DA $(p<0.05)$, which showed no significant dispersal (Figure 1A) and was statistically similar to the non-ethanol control group. 2CP concentrations ranging from 15.625 to
$500 \mu \mathrm{g} / \mathrm{ml}$ dispersed approximately $40-60 \%$ of $P$. aeruginosa biofilm, which was comparable to the dispersion activity of C2DA and T2DA at the same concentrations. Statistical differences between $P$. aeruginosa dispersion between fatty-acid analogs were only observed between 2CP and T2DA at only the $62.5-\mu \mathrm{g} / \mathrm{ml}$ concentration $(p>0.05)$ (Figure 1B).

\section{Inhibition}

The fatty-acid 2CP inhibited bacterial growth at high concentrations, inhibiting $S$. aureus at $1 \mathrm{mg} / \mathrm{ml}$ and $P$. aeruginosa growth at $4 \mathrm{mg} / \mathrm{ml}$. Various concentrations of $2 \mathrm{CP}$ were shown to effectively reduce the MIC of tested antibiotics against both strains by at least $50 \%$, with the exception of only tetracycline and $S$. aureus. Tobramycin was found to have additive effects with 2CP, C2DA, and T2DA against $S$. aureus growth, although $2 \mathrm{CP}$ had the lowest FICI score of 0.31 , compared to 1.0 for C2DA and T2DA (Table 1). Tetracycline and levofloxacin were found to have additive effects with all three fatty acids against $S$. aureus growth. Similarly, tobramycin and tetracycline were additive with all three fatty acids for $P$. aeruginosa inhibition (Table 2). Although additive effects were found for levofloxacin combined with $2 \mathrm{CP}$ against $P$. aeruginosa, indifference or no effect was observed when combined with C2DA or T2DA.

\section{Eradication}

The fatty-acid 2CP was not capable of eradicating $P$. aeruginosa biofilm when applied alone but at the concentration of $1,000 \mu \mathrm{g} / \mathrm{ml}$ was sufficient to eradicate S. aureus. Various concentrations of $2 \mathrm{CP}$ were shown to effectively reduce the MBEC of tobramycin, tetracycline, and levofloxacin against both strains by at least $50 \%$. Tobramycin and tetracycline were found to have additive effects with all three fatty-acid analogs against $S$. aureus growth, although combining $2 \mathrm{CP}$ or $\mathrm{C} 2 \mathrm{DA}$ with levofloxacin it had synergistic effects in eradication of biofilm (Table 3). Tobramycin and levofloxacin were synergistic with 2CP for eradication of $P$. aeruginosa (Table 4). Tetracycline did not result in eradication of $P$. aeruginosa biofilm at the highest concentration studied, which could not be increased in these assays due to solubility limitations.

\section{Cytocompatibility}

$2 \mathrm{CP}$ at concentrations at $500 \mu \mathrm{g} / \mathrm{ml}$ in $2.5 \%$ ethanol, as well as lower concentrations, promoted fibroblast cell viability above $70 \%$ compared to non-ethanol controls, in accordance with the ISO 109935 Biological Evaluations of Medical Devices standard when evaluating biomaterials against fibroblasts. There were no statistically significant differences in cytotoxicity between 2CP and C2DA for any concentration studied; T2DA at concentrations of $500 \mu \mathrm{g} / \mathrm{ml}$ had slightly more viable cells remaining compared to $\mathrm{C} 2 \mathrm{DA}$ and $2 \mathrm{CP}$ but significantly lower cell viability at concentrations of $1,000 \mu \mathrm{g} / \mathrm{ml}$ (Figure 2).

\section{Stability of 2CP and C2DA}

The stability of C2DA and 2CP was determined during shortterm exposure to the UV-activated photoinitiator Irgacure 2959. This system was used to mimic both oxidative degradation and 

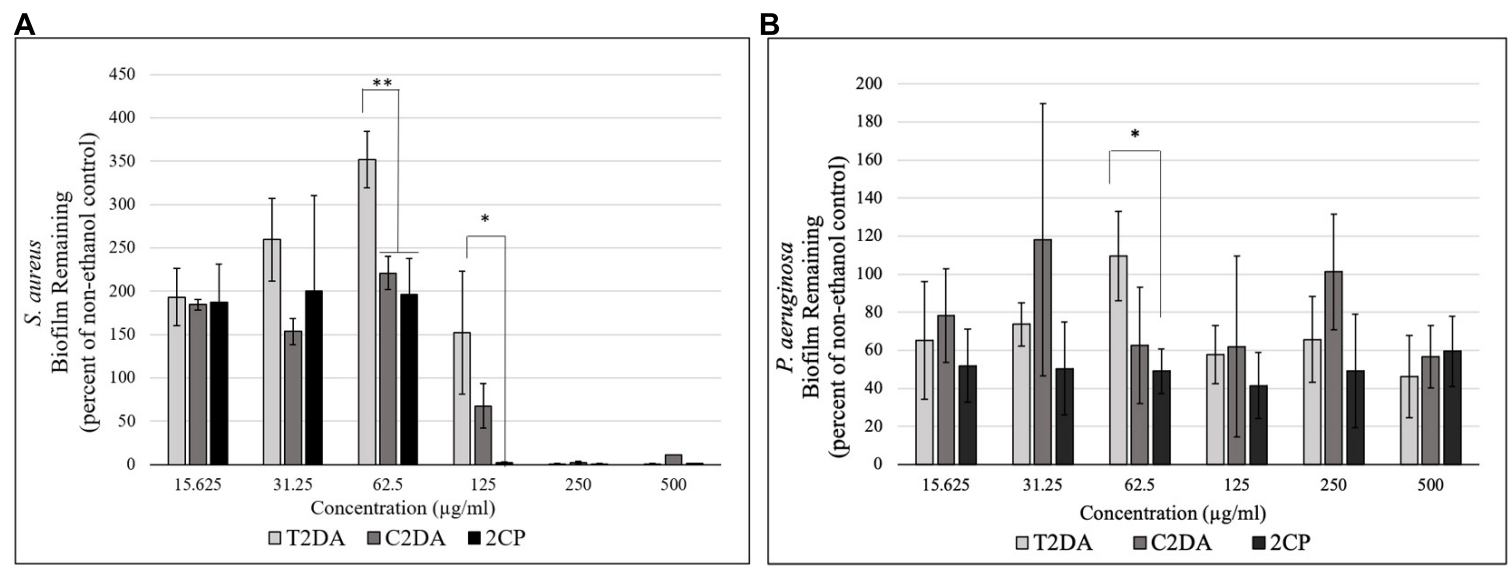

FIGURE 1 | Graph showing the percentage of (A) S. aureus and (B) P. aeruginosa biofilm remaining after 1 h of exposure to T2DA, C2DA, and 2CP. Asterisks represent significantly less biofilm remaining compared to T2DA $\left({ }^{*} p<0.05,{ }^{* *} p<0.01\right)$, detected by one-way ANOVA with the Holm-Sidak post-hoc test. Data represent mean \pm standard deviation.

TABLE 1 |S. aureus fractional inhibitory concentration index values.

\begin{tabular}{|c|c|c|c|c|c|c|}
\hline & $\begin{array}{l}\text { MBIC for 2CP (alone) } \\
\qquad(\mu \mathrm{g} / \mathrm{ml})\end{array}$ & $\begin{array}{c}\text { MBIC for } 2 \mathrm{CP} \\
\text { (combined) }(\mu \mathrm{g} / \mathrm{ml})\end{array}$ & $\begin{array}{l}\text { MBIC for antibiotic } \\
\text { (alone) }(\mu \mathrm{g} / \mathrm{ml})\end{array}$ & $\begin{array}{l}\text { MBIC for antibiotic } \\
\text { (combined) }(\mu \mathrm{g} / \mathrm{ml})\end{array}$ & $\mathrm{FICl}$ & Interpretation \\
\hline \multicolumn{7}{|l|}{ S. aureus } \\
\hline Tobramycin & 1000.0 & 31 & 4.0 & 2.0 & 0.531 & Additive \\
\hline Tetracycline & 1000.0 & 63 & 1.0 & 1.0 & 1.06 & Indifferent \\
\hline \multirow[t]{2}{*}{ Levofloxacin } & 1000.0 & 500 & 1.0 & 0.3 & 0.8 & Additive \\
\hline & $\begin{array}{l}\text { MBIC for C2DA } \\
\text { (alone) }(\mu \mathrm{g} / \mathrm{ml})\end{array}$ & $\begin{array}{c}\text { MBIC for C2DA } \\
\text { (combined) }(\mu \mathrm{g} / \mathrm{ml})\end{array}$ & $\begin{array}{l}\text { MBIC for antibiotic } \\
\text { (alone) }(\mu \mathrm{g} / \mathrm{ml})\end{array}$ & $\begin{array}{l}\text { MBIC for antibiotic } \\
\text { (combined) }(\mu \mathrm{g} / \mathrm{ml})\end{array}$ & $\mathrm{FICl}$ & Interpretation \\
\hline Tobramycin & 1000.0 & 500 & 4.0 & 2.0 & 1.0 & Additive \\
\hline Tetracycline & 1000.0 & 250 & 1.0 & 0.5 & 0.75 & Additive \\
\hline \multirow[t]{2}{*}{ Levofloxacin } & 1000.0 & 250 & 1.0 & 0.5 & 0.75 & Additive \\
\hline & $\begin{array}{l}\text { MBIC for T2DA } \\
\text { (alone) }(\mu \mathrm{g} / \mathrm{ml})\end{array}$ & $\begin{array}{c}\text { MBIC for T2DA } \\
\text { (combined) }(\mu \mathrm{g} / \mathrm{ml})\end{array}$ & $\begin{array}{l}\text { MBIC for antibiotic } \\
\text { (alone) }(\mu \mathrm{g} / \mathrm{ml})\end{array}$ & $\begin{array}{l}\text { MBIC for antibiotic } \\
\text { (combined) }(\mu \mathrm{g} / \mathrm{ml})\end{array}$ & $\mathrm{FICl}$ & Interpretation \\
\hline Tobramycin & 1000.0 & 500 & 4.0 & 2.0 & 1.0 & Additive \\
\hline Tetracycline & 1000.0 & 250 & 1.0 & 0.5 & 0.75 & Additive \\
\hline Levofloxacin & 1000.0 & 250 & 1.0 & 0.5 & 0.75 & Additive \\
\hline
\end{tabular}

Minimum biofilm inhibitory concentration (MBIC) for 2CP, C2DA, and T2DA against S. aureus when treated alone or combined with tobramycin, tetracycline, or levofloxacin. MBIC of each antibiotic against S. aureus alone is also included. These values were used in Equation 1 to determine the fractional inhibitory concentration index for each

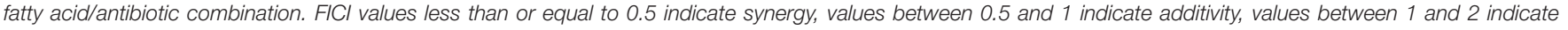
indifference, and values above 2 indicate antagonism.

UV-induced isomerization of the cis-alkene in C2DA. C2DA was completely consumed by the combination of UV and initiator (0.05\% Irgacure, half-life $\sim 20 \mathrm{~min}$, complete degradation by $60 \mathrm{~min}, 0.1 \%$ Irgacure half-life $\sim 10 \mathrm{~min}$, complete degradation by $30 \mathrm{~min}$ ) (Figure 3). C2DA showed no degradation to UV alone out to $4 \mathrm{~h}$ of exposure. In contrast, 2CP showed no degradation to either UV alone or UV plus initiator out to $4 \mathrm{~h}$.

\section{DISCUSSION}

A synthetic strategy for reliable synthesis of C2DA, T2DA, and $2 \mathrm{CP}$ is demonstrated using a combination of Lindlar reduction, Jones oxidation, and cyclopropanation to make all three targets. Our work demonstrates increased activity against $S$. aureus with a cyclopropyl isostere replacing the double bond to attain structural similarity. Chemical mimics or analogs of fatty acids like 2CP may be used in therapeutics for prevention or treatment of biofilm-based infections (Davies and Marques, 2009). Delivered locally or applied topically, 2CP may inhibit formation of biofilms or increase eradication of biofilms on implants or tissue, especially when combined with antibiotic administration. The cyclopropanated analogs have reduced isomerization and degradation when exposed to UV in the presence of a photoinitiator and thus may have better shelf stability. Further, as $2 \mathrm{CP}$ is an analog of natural diffusible 
TABLE 2 |P. aeruginosa fractional inhibitory concentration index values.

\begin{tabular}{|c|c|c|c|c|c|c|}
\hline & $\begin{array}{c}\text { MBIC for 2CP (alone) } \\
(\mu \mathrm{g} / \mathrm{ml})\end{array}$ & $\begin{array}{c}\text { MBIC for } 2 \mathrm{CP} \\
\text { (combined) }(\mu \mathrm{g} / \mathrm{ml})\end{array}$ & $\begin{array}{l}\text { MBIC for antibiotic } \\
\text { (alone) }(\mu \mathrm{g} / \mathrm{ml})\end{array}$ & $\begin{array}{l}\text { MBIC for antibiotic } \\
\text { (combined) }(\mu \mathrm{g} / \mathrm{ml})\end{array}$ & $\mathrm{FICl}$ & Interpretation \\
\hline \multicolumn{7}{|c|}{ P. aeruginosa } \\
\hline Tobramycin & 4,000 & 31 & 0.5 & 0.25 & 0.508 & Additive \\
\hline Tetracycline & 4,000 & 1,000 & 32 & 16 & 0.75 & Additive \\
\hline \multirow[t]{2}{*}{ Levofloxacin } & 4,000 & 1,000 & 4.0 & 2 & 0.75 & Additive \\
\hline & $\begin{array}{l}\text { MBIC for C2DA } \\
\text { (alone) }(\mu \mathrm{g} / \mathrm{ml})\end{array}$ & $\begin{array}{c}\text { MBIC for C2DA } \\
\text { (combined) }(\mu \mathrm{g} / \mathrm{ml})\end{array}$ & $\begin{array}{l}\text { MBIC for antibiotic } \\
\text { (alone) }(\mu \mathrm{g} / \mathrm{ml})\end{array}$ & $\begin{array}{l}\text { MBIC for antibiotic } \\
\text { (combined) }(\mu \mathrm{g} / \mathrm{ml})\end{array}$ & $\mathrm{FICl}$ & Interpretation \\
\hline Tobramycin & 4,000 & 125 & 0.5 & 0.25 & 0.531 & Additive \\
\hline Tetracycline & 4,000 & 500 & 32 & 16 & 0.625 & Additive \\
\hline \multirow[t]{2}{*}{ Levofloxacin } & 4,000 & 4,000 & 4.0 & 4.0 & 2.0 & Indifferent \\
\hline & $\begin{array}{l}\text { MBIC for T2DA } \\
\text { (alone) }(\mu \mathrm{g} / \mathrm{ml})\end{array}$ & $\begin{array}{c}\text { MBIC for T2DA } \\
\text { (combined) }(\mu \mathrm{g} / \mathrm{ml})\end{array}$ & $\begin{array}{l}\text { MBIC for antibiotic } \\
\text { (alone) }(\mu \mathrm{g} / \mathrm{ml})\end{array}$ & $\begin{array}{l}\text { MBIC for antibiotic } \\
\text { (combined) }(\mu \mathrm{g} / \mathrm{ml})\end{array}$ & FICI & Interpretation \\
\hline Tobramycin & 4,000 & 125 & 0.5 & 0.3 & 0.631 & Additive \\
\hline Tetracycline & 4,000 & 1,000 & 32 & 16 & 0.75 & Additive \\
\hline Levofloxacin & 4,000 & 4,000 & 4.0 & 4.0 & 2.0 & Indifferent \\
\hline
\end{tabular}

TABLE 3 | S. aureus FBEC index values.

\begin{tabular}{|c|c|c|c|c|c|c|}
\hline & $\begin{array}{l}\text { MBEC for } 2 C P \\
\text { (alone) }(\mu \mathrm{g} / \mathrm{ml})\end{array}$ & $\begin{array}{c}\text { MBEC for } 2 \mathrm{CP} \\
\text { (combined) }(\mu \mathrm{g} / \mathrm{ml})\end{array}$ & $\begin{array}{l}\text { MBEC for antibiotic } \\
\text { (alone) }(\mu \mathrm{g} / \mathrm{ml})\end{array}$ & $\begin{array}{l}\text { MBEC for antibiotic } \\
\text { (combined) }(\mu \mathrm{g} / \mathrm{ml})\end{array}$ & FBEC & Interpretation \\
\hline \multicolumn{7}{|l|}{ S. aureus } \\
\hline Tobramycin & 1,000 & 31.25 & 2.5 & 1.25 & 0.531 & Additive \\
\hline Tetracycline & 1,000 & 125 & 1.25 & 0.625 & 0.625 & Additive \\
\hline \multirow[t]{2}{*}{ Levofloxacin } & 1,000 & 250 & 1 & 0.25 & 0.5 & Synergistic \\
\hline & $\begin{array}{l}\text { MBEC for C2DA } \\
\text { (alone) }(\mu \mathrm{g} / \mathrm{ml})\end{array}$ & $\begin{array}{c}\text { MBEC for C2DA } \\
\text { (combined) }(\mu \mathrm{g} / \mathrm{ml})\end{array}$ & $\begin{array}{l}\text { MBEC for antibiotic } \\
\text { (alone) }(\mu \mathrm{g} / \mathrm{ml})\end{array}$ & $\begin{array}{l}\text { MBEC for antibiotic } \\
\text { (combined) }(\mu \mathrm{g} / \mathrm{ml})\end{array}$ & FBEC & Interpretation \\
\hline Tobramycin & 1,000 & 125 & 2.5 & 1.25 & 0.625 & Additive \\
\hline Tetracycline & 1,000 & 500 & 1 & 0.25 & 0.75 & Additive \\
\hline \multirow[t]{2}{*}{ Levofloxacin } & 1,000 & 125 & 1 & 0.25 & 0.375 & Synergistic \\
\hline & $\begin{array}{l}\text { MBEC for T2DA } \\
\text { (alone) }(\mu \mathrm{g} / \mathrm{ml})\end{array}$ & $\begin{array}{c}\text { MBEC for T2DA } \\
\text { (combined) }(\mu \mathrm{g} / \mathrm{ml})\end{array}$ & $\begin{array}{l}\text { MBEC for antibiotic } \\
\text { (alone) }(\mu \mathrm{g} / \mathrm{ml})\end{array}$ & $\begin{array}{l}\text { MBEC for antibiotic } \\
\text { (combined) }(\mu \mathrm{g} / \mathrm{ml})\end{array}$ & FBEC & Interpretation \\
\hline Tobramycin & 1,000 & 125 & 2.5 & 1.25 & 0.625 & Additive \\
\hline Tetracycline & 1,000 & 500 & 1 & 0.25 & 0.75 & Additive \\
\hline Levofloxacin & 1,000 & 500 & 1 & 0.25 & 0.75 & Additive \\
\hline
\end{tabular}

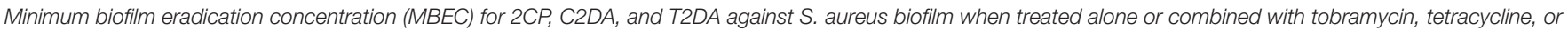

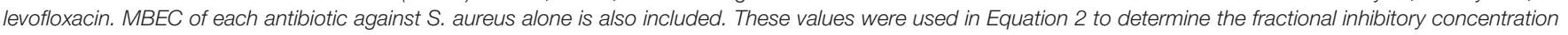

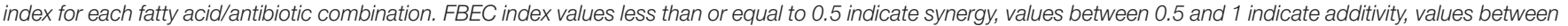
1 and 2 indicate indifference, and values above 2 indicate antagonism.

signaling factor molecules, presence of this fatty acid is not likely to drive bacterial resistance due to selective pressure, although this has not been evaluated in the current study.

The tolerance of biofilms to antimicrobials and persistence of biofilm infections can cause unique challenges for the treatment of infections. Numerous methods are adopted for the disruption, inhibition, and eradication of biofilms. 2CP showed dispersal of biofilms, although at higher concentrations than were observed in studies of C2DA by Davies and Marques (2009). Potential reasons for these discrepancies may include use of different commercial suppliers or synthetic routes. C2DA isolated from biological spent media may also be enantiopure, which may explain the higher activity of chloroform-extracted media used in studies by Davies and Marques (2009). We are currently working to separate the two $2 \mathrm{CP}$ enantiomers via conversion to diastereomeric analogs using chiral alcohols, although this work was done 
TABLE 4 | P. aeruginosa fractional eradication concentration index values.

\begin{tabular}{|c|c|c|c|c|c|c|}
\hline & $\begin{array}{l}\text { MBEC for } 2 C P \\
\text { (alone) }(\mu \mathrm{g} / \mathrm{ml})\end{array}$ & $\begin{array}{c}\text { MBEC for } 2 \mathrm{CP} \\
\text { (combined) }(\mu \mathrm{g} / \mathrm{ml})\end{array}$ & $\begin{array}{l}\text { MBEC for antibiotic } \\
\text { (alone) }(\mu \mathrm{g} / \mathrm{ml})\end{array}$ & $\begin{array}{l}\text { MBEC for antibiotic } \\
\text { (combined) }(\mu \mathrm{g} / \mathrm{ml})\end{array}$ & FBEC & Interpretation \\
\hline \multicolumn{7}{|c|}{ P. aeruginosa } \\
\hline Tobramycin & $>4,000$ & 250 & 500 & 150 & 0.363 & Synergistic \\
\hline Tetracycline & $>4,000$ & ND & ND & ND & ND & ND \\
\hline \multirow[t]{2}{*}{ Levofloxacin } & $>4,000$ & 250 & 312 & 78 & 0.313 & Synergistic \\
\hline & $\begin{array}{l}\text { MBEC for C2DA } \\
\text { (alone) }(\mu \mathrm{g} / \mathrm{ml})\end{array}$ & $\begin{array}{c}\text { MBEC for C2DA } \\
\text { (combined) }(\mu \mathrm{g} / \mathrm{ml})\end{array}$ & $\begin{array}{l}\text { MBEC for antibiotic } \\
\text { (alone) }(\mu \mathrm{g} / \mathrm{ml})\end{array}$ & $\begin{array}{l}\text { MBEC for antibiotic } \\
\text { (combined) }(\mu \mathrm{g} / \mathrm{ml})\end{array}$ & FBEC & Interpretation \\
\hline Tobramycin & $>4,000$ & 250 & 2500 & 625 & 0.313 & Synergistic \\
\hline Tetracycline & $>4,000$ & ND & ND & ND & ND & ND \\
\hline \multirow[t]{2}{*}{ Levofloxacin } & $>4,000$ & 500 & 312 & 78 & 0.375 & Synergistic \\
\hline & $\begin{array}{l}\text { MBEC for T2DA } \\
\text { (alone) }(\mu \mathrm{g} / \mathrm{ml})\end{array}$ & $\begin{array}{c}\text { MBEC for T2DA } \\
\text { (combined) }(\mu \mathrm{g} / \mathrm{ml})\end{array}$ & $\begin{array}{l}\text { MBEC for antibiotic } \\
\text { (alone) }(\mu \mathrm{g} / \mathrm{ml})\end{array}$ & $\begin{array}{l}\text { MBEC for antibiotic } \\
\text { (combined) }(\mu \mathrm{g} / \mathrm{ml})\end{array}$ & FBEC & Interpretation \\
\hline Tobramycin & $>4,000$ & 250 & 2,500 & 625 & 0.313 & Synergistic \\
\hline Tetracycline & $>4,000$ & ND & ND & ND & ND & ND \\
\hline Levofloxacin & $>4,000$ & 500 & 312 & 78 & 0.375 & Synergistic \\
\hline
\end{tabular}

Minimum biofilm eradication concentration (MBEC) for 2CP, C2DA, and T2DA against P. aeruginosa biofilm when treated alone or combined with tobramycin, tetracycline,

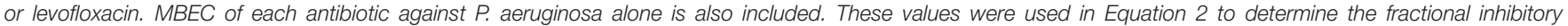
concentration index for each fatty acid/antibiotic combination. FBEC index values less than or equal to 0.5 indicate synergy, values between 0.5 and 1 indicate additivity, values between 1 and 2 indicate indifference, and values above 2 indicate antagonism.

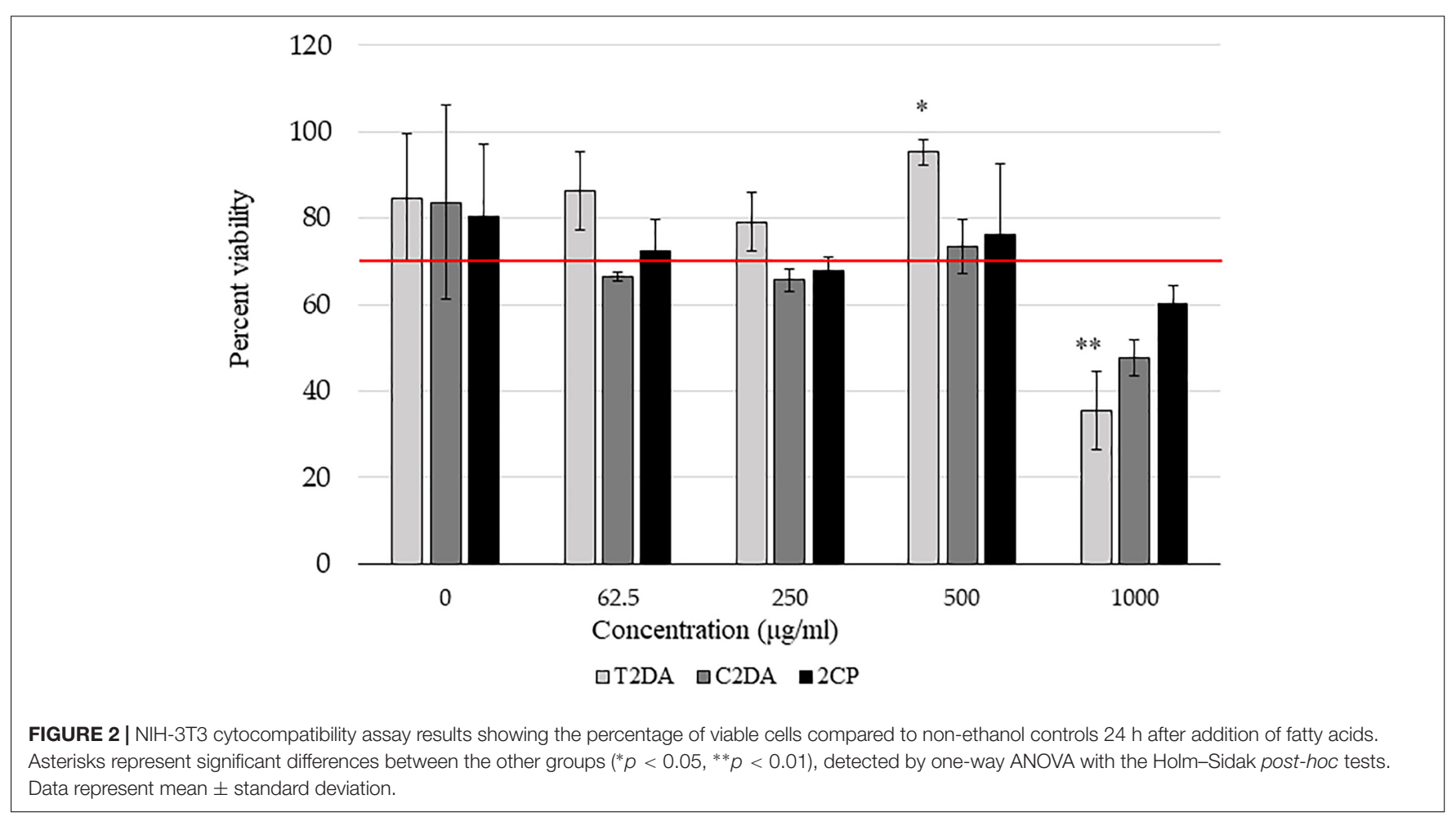

using the racemic mixture. Furthermore, methods to quantify biofilms vary greatly between previous studies, which may further explain differences seen in effective concentrations. RahmaniBadi et al. observed two- to three-fold increases in the number of planktonic cells of mixed species biofilms after treatment with $310 \mathrm{nM}$ C2DA in models of catheter infection and dental plaque removal (Rahmani-Badi et al., 2014, 2015a). The activity of the trans-isomer against $P$. aeruginosa is consistent with studies by Davies et al. where T2DA showed dispersal activity in the concentration range reported here, although the C2DA analog dispersed biofilms at a much lower concentration (Davies and Marques, 2009). T2DA is also known as a Streptococcal DSF (SDSF), produced by Streptococcus mutans with inhibitory effects on fungal hyphae (Vílchez et al., 2010). 

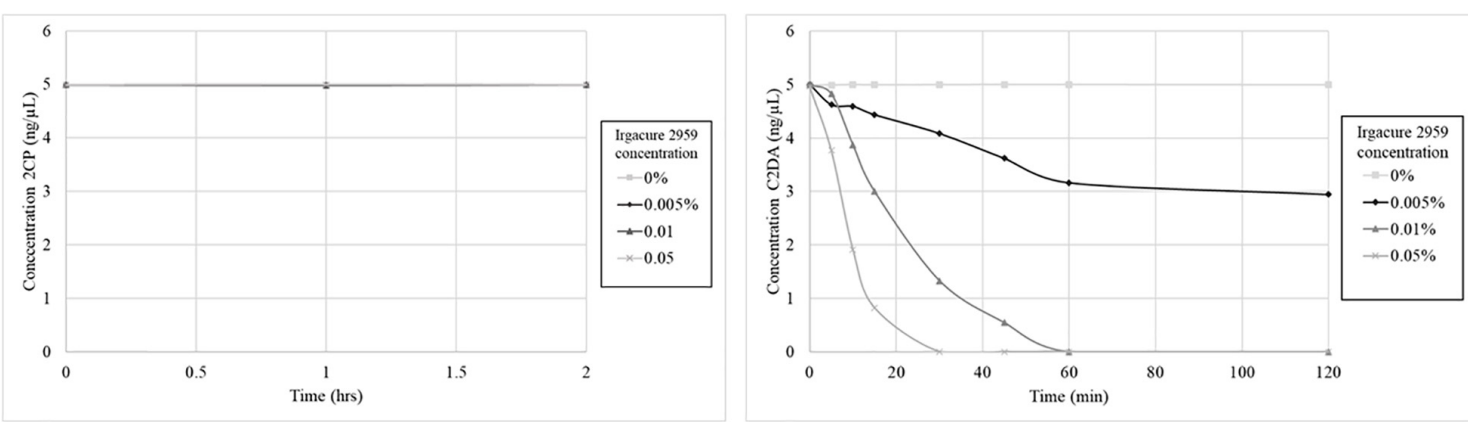

FIGURE 3 | Graphs show 2CP (left) and C2DA (right) short term solution stability over time (4 h total, $2 \mathrm{~h}$ shown) and concentration dependence of DSF stability when challenged with UV and the photoinitiator Irgacure.

DSF molecules are known to have mechanisms of action that differ between strains at least in the site of action, external or internal to the cell. In Xanthomonas and Pseudomonas, DSF binds to specific transmembrane protein receptors and activates genetic transcription (Van Houdt and Michiels, 2010; RahmaniBadi et al., 2015b; Ryan et al., 2015; Suppiger et al., 2016). In Burkholderia cenocepacia, DSF diffuse across the membrane to bind to cytosolic proteins to activate transcriptional changes (Suppiger et al., 2016). Cui et al. (2019) developed a DSF analog that was capable of interfering with Burkholderia cenocepacia quorum sensing and virulence, demonstrating its potential as a novel antibacterial agent. Similarly, Huedo et al. (2019) developed DSF that could interfere with quorum sensing of both Stenotrophomonas maltophilia and Burkholderia cepacia. Su et al. (2011) synthesized 4,5-disubstituted-2-aminoimidazole-triazole conjugates that inhibited $S$. aureus at micromolar concentrations and Acinetobacter baumannii at slightly higher concentrations, with dispersal and inhibition activity two orders of magnitude greater than C2DA. While mechanisms of action for DSF are not entirely elucidated, our cyclopropyl analog has a similar structure to C2DA and other DSF molecules and thus may have similar biological interactions with receptors and cell membranes. In one dispersal study, Rahmani-Badi et al. (2015b) have identified protein transcription changes occurring in $P$. aeruginosa upon stimulation with C2DA, identifying a cluster of genes implicated in sensing and responding to fatty-acid signals, including regulation of pathogenicity factor (rpf) proteins. It has also been shown that the histidine kinase PA1396 in P. aeruginosa is a major factor in DSF function; certain DSF analogs are able to block the ability of PA1396 to autophosphorylate, which subsequently reduces biofilm formation and antibiotic tolerance both in vitro and in vivo (An et al., 2019). Previous research has also demonstrated that C2DA increased membrane permeability of $P$. aeruginosa and S. aureus (Masters et al., 2016), which may occur by substitution of membrane phospholipids by fatty acid or by stimulating proton-motive force at the membrane (Meylan et al., 2017). Compared to enzymatic dispersal agents such as enzymatic hydrolases that degrade the EPS matrix (Fleming et al., 2017), 2-decenoic acid analogs appear to act at the cellular level and do not directly affect EPS (Marques et al., 2015).
In order to have clinical relevance as a prophylactic agent, biofilm inhibitors should also prevent planktonic bacterial growth and attachment to surfaces. Previous work has shown that C2DA has additive or synergistic growth- and biofilminhibitory effects with many common antibiotics including vancomycin, linezolid, tetracycline, amikacin, and ciprofloxacin (Marques et al., 2015; Masters et al., 2016; Harris et al., 2017). The present study indicates that $2 \mathrm{CP}$ maintains additive or synergistic effects with these antibiotics against both grampositive and gram-negative pathogens. Similar results have been observed with drugs that target quorum sensing pathways, thereby keeping bacteria in the more susceptible planktonic state (Christensen et al., 2012; Yang et al., 2012; Roy et al., 2013). C2DA, T2DA, and the synthetic analog 2CP may be advantageous compared to antibiotic drugs because they are a natural part of the biofilm regulatory process, thereby reducing the risk of pathogens acquiring resistance (Rahmani-Badi et al., 2015b). While it has not been determined whether combining 2-decenoic acids or their analogs decrease or increase the likelihood of antimicrobial resistance, combinatorial effects should improve the efficacy of prophylactic antibiotic therapy by preventing bacterial attachment and reducing the amount of drug needed for bacterial clearance. The tobramycin-2CP combination is especially promising due to the low concentration of $2 \mathrm{CP}$ needed for inhibition or eradication of both bacterial strains, as well as the prevalence of tobramycin in many current local drug delivery systems.

Use of biofilm dispersal agents in the absence of antimicrobials could lead to negative effects on the host, including seeding of further infection sites and septicemia (Fleming and Rumbaugh, 2018). The present study found that $2 \mathrm{CP}$ increased susceptibility of established biofilms to eradication by antimicrobials, which may be due to its activity in stimulating dormant bacterial cell metabolism, which plays a major role in the antimicrobial tolerance of bacteria within biofilms (Del Pozo and Patel, 2007). Although the current study did not specifically select for persister cell populations, studies of C2DA have shown that it can revert persister cell status by increasing the respiratory activity of the cells (Marques et al., 2014). Studies by Marques et al. also demonstrated that in contrast with other metabolites such as sugars that awaken persister cells (Allison et al., 2011), 
C2DA is not used by bacteria as a carbon source for growth (Marques et al., 2014). The 2CP analog would not be expected to be utilized as a carbon source and further would have increased structural stability that would improve long-term storage and sterilization for healthcare applications. Biomaterial systems for co-delivery of antimicrobials and fatty-acid biofilm-disrupting agents have included direct application (Sepehr et al., 2014), biopolymer particles or sponges (Jennings et al., 2012), or implant coatings (Harris et al., 2017). While we did not study persister phenotypes specifically, future studies may explore the effects of this molecule on persisters.

For healthcare applications, targeting biofilm disruption without adverse effects on tissue is critical for the development of therapeutics for treating biofilm-based infection. We observed that the cyclopropyl moiety did not change the biocompatibility profile, with similar results to previous evaluations of cellular viability responses (Jennings et al., 2012; Rawson et al., 2014). A limitation of the current study is the use of a fibroblast cell line for preliminary evaluation of biocompatibility. Other studies of bone cell lines have shown that below certain concentration thresholds, fatty-acid biofilm inhibitors did not interfere with bone cell viability or mineralization (Harris et al., 2017). In an in vivo evaluation or orthopedic infection, a similar molecule C2DA applied to implants in phosphatidylcholine coatings was found to inhibit biofilm formation and no adverse events or increased inflammation in tissue were observed (Harris et al., 2017). Our preliminary stability evaluation indicates that $2 \mathrm{CP}$ is stable in environmental extremes, which may be favorable for sterilization or incorporation into controlled delivery systems. Longer-term and milder degradation experiments are currently underway to confirm enhanced the shelf stability of 2CP. Expanded preclinical evaluations, including studies on inflammatory cell effects, bone cell response, and in vivo infection models, are needed to fully evaluate the potential of $2 \mathrm{CP}$ as a clinical therapeutic. Another limitation of this study is the use of microtiter plate-based assays; while they were adequate for this pilot study, future studies will include additional biofilm assays to confirm results, in addition to experiments that may specifically identify effects of 2CP on gene expression and phenotype as well as sensing mechanisms for different bacteria. Evaluation of 2CP activity in dynamic conditions such as bioreactor culture could complement these results. While this study established preliminary efficacy against two representative strains of bacteria, future studies may also incorporate mixed cultures of different strains of bacteria as well as fungi.

We have demonstrated a successful synthetic route for cyclopropanated analogs of 2-decenoic acid, replacing the double bond in cis-configuration with a cyclopropyl ring. This

\section{REFERENCES}

Allison, K. R., Brynildsen, M. P., and Collins, J. J. (2011). Metabolite-enabled eradication of bacterial persisters by aminoglycosides. Nature 473, 216-220. doi: $10.1038 /$ nature 10069

Amari, D. T., Marques, C. N., and Davies, D. G. (2013). The putative enoyl-coenzyme a hydratase DspI is required for production of analog had similar or improved bioactivity in biofilm dispersal, inhibition, and eradication. Additive and synergistic effects when 2CP is combined with antimicrobials may be clinically useful in applications to treat implant-associated infection, dental plaque removal, or surface decontamination. Future work will explore methods for sustained delivery, evaluate long-term stability and activity, and expand preclinical investigations to determine potential as a clinical therapeutic.

\section{DATA AVAILABILITY STATEMENT}

The raw data supporting the conclusions of this article will be made available by the authors, without undue reservation.

\section{AUTHOR CONTRIBUTIONS}

JJ and DB conceived this idea and determined the methodology. BR synthesized the fatty acids and performed the chemical analysis and validation. $\mathrm{ZH}, \mathrm{RA}$, and $\mathrm{MH}$ conducted the biofilm studies and performed the bacteriological analysis. $\mathrm{BH}$ performed the stability evaluation and all authors contributed to the original draft preparation. $\mathrm{ZH}, \mathrm{JJ}$, and $\mathrm{DB}$ reviewed and edited the final forms of this manuscript. JJ and DB acquired the funding, were administrators of this project, and supervised the other authors.

\section{FUNDING}

This research was supported by the FedEx Institute of Technology with a development grant under award no. 241109 and the National Institute of Arthritis and Musculoskeletal and Skin Disease of the National Institute of Health (NIH) under award no. R01 AR066050.

\section{ACKNOWLEDGMENTS}

We acknowledge the assistance of Landon Choi, Emily Coleman, and Stasianne Mallin in performing the laboratory experiments.

\section{SUPPLEMENTARY MATERIAL}

The Supplementary Material for this article can be found online at: https://www.frontiersin.org/articles/10.3389/fmicb. 2021.645180/full\#supplementary-material

the Pseudomonas aeruginosa biofilm dispersion autoinducer cis2-decenoic acid. J. Bacteriol. 195, 4600-4610. doi: 10.1128/jb.00 707-13

An, S.-Q., Murtagh, J., Twomey, K. B., Gupta, M. K., O’Sullivan, T. P., Ingram, R., et al. (2019). Modulation of antibiotic sensitivity and biofilm formation in Pseudomonas aeruginosa by interspecies signal analogues. Nat.Commun. 10:2334. 
Barraud, N., Buson, A., Jarolimek, W., and Rice, S. A. (2013). Mannitol enhances antibiotic sensitivity of persister bacteria in Pseudomonas aeruginosa biofilms. PLoS One 8:e84220. doi: 10.1371/journal.pone.0084220

Batoni, G., Maisetta, G., and Esin, S. (2016). Antimicrobial peptides and their interaction with biofilms of medically relevant bacteria. Biochim. Biophys. Acta 1858, 1044-1060. doi: 10.1016/j.bbamem.2015.10.013

Bauer, T., and Grosso, M. (2013). The basic science of biofilm and its relevance to the treatment of periprosthetic joint infection. Orthop. Knowl. Online J. 11, 12-20.

Brady, R. A., Leid, J. G., Camper, A. K., Costerton, J. W., and Shirtliff, M. E. (2006). Identification of Staphylococcus aureus proteins recognized by the antibody-mediated immune response to a biofilm infection. Infection Immun. 74, 3415-3426. doi: 10.1128/iai.00392-06

Christensen, L. D., van Gennip, M., Jakobsen, T. H., Alhede, M., Hougen, H. P., Høiby, N., et al. (2012). Synergistic antibacterial efficacy of early combination treatment with tobramycin and quorum-sensing inhibitors against Pseudomonas aeruginosa in an intraperitoneal foreign-body infection mouse model. J. Antimicrob. Chemother. 67, 1198-1206. doi: 10.1093/jac/ dks002

Cui, C., Song, S., Yang, C., Sun, X., Huang, Y., Li, K., et al. (2019). Disruption of quorum sensing and virulence in Burkholderia cenocepacia by a structural analogue of the cis-2-dodecenoic acid signal. Appl. Environ. Microbiol. 85, e00105-e00119.

Czaczyk, K., and Myszka, K. (2007). Biosynthesis of extracellular polymeric substances (EPS) and its role in microbial biofilm formation. Pol. J. Environ. Stud. 16, 799-806.

Davies, D. G., and Marques, C. N. (2009). A fatty acid messenger is responsible for inducing dispersion in microbial biofilms. J. Bacteriol. 191, 1393-1403. doi: 10.1128/jb.01214-08

de Breij, A., Riool, M., Kwakman, P. H., de Boer, L., Cordfunke, R. A., Drijfhout, J. W., et al. (2016). Prevention of Staphylococcus aureus biomaterial-associated infections using a polymer-lipid coating containing the antimicrobial peptide OP-145. J. Control. Release 222, 1-8. doi: 10.1016/j.jconrel.2015.12.003

Del Pozo, J., and Patel, R. (2007). The challenge of treating biofilm-associated bacterial infections. Clin. Pharmacol. Ther. 82, 204-209. doi: 10.1038/sj.clpt. 6100247

Dosler, S., and Karaaslan, E. (2014). Inhibition and destruction of Pseudomonas aeruginosa biofilms by antibiotics and antimicrobial peptides. Peptides 62, 32-37. doi: 10.1016/j.peptides.2014.09.021

Dugave, C., and Demange, L. (2003). Cis- trans isomerization of organic molecules and biomolecules: implications and applications. Chem. Rev. 103, 2475-2532. doi: $10.1021 / \mathrm{cr} 0104375$

European Committee for Antimicrobial Susceptibility Testing (EUCAST) of the European Society of Clinical Microbiology and Infectious Dieases (ESCMID). (2000). Terminology relating to methods for the determination of susceptibility of bacteria to antimicrobial agents. Clin. Microbiol. Infect. 6, 503-508. doi: 10.1046/j.1469-0691.2000.00149.x

Fleming, D., and Rumbaugh, K. (2018). The consequences of biofilm dispersal on the host. Sci. Rep. 8:10738.

Fleming, G., Aveyard, J., Fothergill, J. L., McBride, F., Raval, R., and D'Sa, R. A. (2017). Nitric oxide releasing polymeric coatings for the prevention of biofilm formation. Polymers 9:601. doi: 10.3390/polym9110601

Flemming, H.-C. (2016). "The perfect slime-and the 'dark matter'of biofilms," in The Perfect Slime: Microbial Extracellular Polymeric Substances, eds H.-C. Flemming, T. R. Neu, and J. Wingender (Heidelberg, NY: Springer), 1-14.

Flemming, H.-C., Wingender, J., Szewzyk, U., Steinberg, P., Rice, S. A., and Kjelleberg, S. (2016). Biofilms: an emergent form of bacterial life. Nat. Rev. Microbiol. 14, 563-567. doi: 10.1038/nrmicro.2016.94

Harris, M. A., Beenken, K. E., Smeltzer, M. S., Haggard, W. O., and Jennings, J. A. (2017). Phosphatidylcholine coatings deliver local antimicrobials and reduce infection in a murine model: a preliminary study. Clin. Orthop. Relat. Res. 475, 1847-1853. doi: 10.1007/s11999-016-5211-7

Hochbaum, A. I., Kolodkin-Gal, I., Foulston, L., Kolter, R., Aizenberg, J., and Losick, R. (2011). Inhibitory effects of D-amino acids on Staphylococcus aureus biofilm development. J. Bacteriol. 193, 5616-5622. doi: 10.1128/jb.05534-11

Huedo, P., Kumar, V. P., Horgan, C., Yero, D., Daura, X., Gibert, I., et al. (2019). Sulfonamide-based diffusible signal factor analogs interfere with quorum sensing in Stenotrophomonas maltophilia and Burkholderia cepacia. Future Med. Chem. 11, 1565-1582. doi: 10.4155/fmc-2019-0015

Jennings, J. A., Courtney, H. S., and Haggard, W. O. (2012). Cis-2-decenoic acid inhibits S. aureus growth and biofilm in vitro: a pilot study. Clin. Orthop. Relat. Res. 470, 2663-2670. doi: 10.1007/s11999-012-2388-2

Jennings, L. K., Storek, K. M., Ledvina, H. E., Coulon, C., Marmont, L. S., Sadovskaya, I., et al. (2015). Pel is a cationic exopolysaccharide that cross-links extracellular DNA in the Pseudomonas aeruginosa biofilm matrix. Proc. Natl. Acad. Sci. 112, 11353-11358. doi: 10.1073/pnas.1503058112

Keren, I., Kaldalu, N., Spoering, A., Wang, Y., and Lewis, K. (2004). Persister cells and tolerance to antimicrobials. FEMS Microbiol. Lett. 230, 13-18. doi: 10.1016/s0378-1097(03)00856-5

Marques, C. N., Davies, D. G., and Sauer, K. (2015). Control of biofilms with the fatty acid signaling molecule cis-2-decenoic acid. Pharmaceuticals 8, 816-835. doi: $10.3390 /$ ph8040816

Marques, C. N., Morozov, A., Planzos, P., and Zelaya, H. M. (2014). The fatty acid signaling molecule cis-2-decenoic acid increases metabolic activity and reverts persister cells to an antimicrobial-susceptible state. Appl. Environ. Microbiol. 80, 6976-6991. doi: 10.1128/aem.01576-14

Masters, E., Harris, M., and Jennings, J. (2016). Cis-2-decenoic acid interacts with bacterial cell membranes to potentiate additive and synergistic responses against biofilm. J. Bacteriol. Mycol. 3, 1031-1038.

Meylan, S., Porter, C. B., Yang, J. H., Belenky, P., Gutierrez, A., Lobritz, M. A., et al. (2017). Carbon sources tune antibiotic susceptibility in Pseudomonas aeruginosa via tricarboxylic acid cycle control. Cell Chem. Biol. 24, 195-206. doi: 10.1016/j.chembiol.2016.12.015

Molin, S., and Tolker-Nielsen, T. (2003). Gene transfer occurs with enhanced efficiency in biofilms and induces enhanced stabilisation of the biofilm structure. Curr. Opin. Biotechnol. 14, 255-261. doi: 10.1016/s0958-1669(03) 00036-3

Nickzad, A., and Déziel, E. (2014). The involvement of rhamnolipids in microbial cell adhesion and biofilm development-an approach for control? Lett. Appl. Microbiol. 58, 447-453. doi: 10.1111/lam.12211

Pace, L. R., Harrison, Z. L., Brown, M. N., Haggard, W. O., and Jennings, J. A. (2019). Characterization and anti-biofilm activity of mannitol-chitosan blended paste for local antibiotic delivery system. Mar. Drugs 17:517. doi: 10.3390/ md17090517

Rahmani-Badi, A., Sepehr, S., and Babaie-Naiej, H. (2015a). A combination of cis2-decenoic acid and chlorhexidine removes dental plaque. Arch. Oral Biol. 60, 1655-1661. doi: 10.1016/j.archoralbio.2015.08.006

Rahmani-Badi, A., Sepehr, S., Fallahi, H., and Heidari-Keshel, S. (2015b). Dissection of the cis-2-decenoic acid signaling network in Pseudomonas aeruginosa using microarray technique. Front. Microbiol. 6:383. doi: 10.3389/ fmicb.2015.00383

Rahmani-Badi, A., Sepehr, S., Mohammadi, P., Soudi, M. R., Babaie-Naiej, H., and Fallahi, H. (2014). A combination of cis-2-decenoic acid and antibiotics eradicates pre-established catheter-associated biofilms. J. Med. Microbiol. 63, 1509-1516. doi: 10.1099/jmm.0.075374-0

Rawson, M., Haggard, W., and Jennings, J. A. (2014). Osteocompatibility of biofilm inhibitors. Open Orthop. J. 8, 442. doi: 10.2174/187432500140801 0442

Roy, V., Meyer, M. T., Smith, J. A., Gamby, S., Sintim, H. O., Ghodssi, R., et al. (2013). AI-2 analogs and antibiotics: a synergistic approach to reduce bacterial biofilms. Appl. Microbiol. Biotechnol. 97, 2627-2638. doi: 10.1007/s00253-0124404-6

Ryan, R. P., An, S. Q., Allan, J. H., McCarthy, Y., and Dow, J. M. (2015). The DSF family of cell-cell signals: an expanding class of bacterial virulence regulators. PLoS Pathog. 11:e1004986. doi: 10.1371/journal.ppat.100 4986

Ryan, R. P., and Dow, J. M. (2011). Communication with a growing family: diffusible signal factor (DSF) signaling in bacteria. Trends Microbiol. 19, 145152. doi: $10.1016 /$ j.tim.2010.12.003

Saeed, K., McLaren, A. C., Schwarz, E. M., Antoci, V., Arnold, W. V., Chen, A. F., et al. (2019). 2018 international consensus meeting on musculoskeletal infection: summary from the biofilm workgroup and consensus on biofilm related musculoskeletal infections. J. Orthop. Res. 37, 1007-1017. doi: 10.1002/ jor.24229 
Sepehr, S., Rahmani-Badi, A., Babaie-Naiej, H., and Soudi, M. R. (2014). Unsaturated fatty acid, cis-2-decenoic acid, in combination with disinfectants or antibiotics removes pre-established biofilms formed by food-related bacteria. PLoS ONE 9:e101677. doi: 10.1371/journal.pone.0101677

Solano, C., Echeverz, M., and Lasa, I. (2014). Biofilm dispersion and quorum sensing. Curr. Opin. Microbiol. 18, 96-104. doi: 10.1016/j.mib.2014.02.008

Stoodley, P., Hall-Stoodley, L., Costerton, B., DeMeo, P., Shirtliff, M., Gawalt, E., et al. (2013). "5 - biofilms, biomaterials, and device-related infections," in Handbook of Polymer Applications in Medicine and Medical Devices, eds K. Modjarrad and S. Ebnesajjad (Oxford: William Andrew Publishing), 77-101.

Su, Z., Peng, L., Worthington, R. J., and Melander, C. (2011). Evaluation of 4,5disubstituted-2-aminoimidazole-triazole conjugates for antibiofilm/antibiotic resensitization activity against MRSA and Acinetobacter baumannii. Chemmedchem 6, 2243-2251. doi: 10.1002/cmdc.201100316

Suppiger, A., Aguilar, C., and Eberl, L. (2016). Evidence for the widespread production of DSF family signal molecules by members of the genus Burkholderia by the aid of novel biosensors. Environ. Microbiol. Rep. 8, 38-44. doi: $10.1111 / 1758-2229.12348$

Tipnis, N. P., and Burgess, D. J. (2018). Sterilization of implantable polymer-based medical devices: a review. Int. J. Pharm. 544, 455-460.

Van Houdt, R., and Michiels, C. W. (2010). Biofilm formation and the food industry, a focus on the bacterial outer surface. J. Appl. Microbiol. 109, $1117-$ 1131. doi: 10.1111/j.1365-2672.2010.04756.x
Vílchez, R., Lemme, A., Ballhausen, B., Thiel, V., Schulz, S., Jansen, R., et al. (2010). Streptococcus mutans inhibits Candida albicans hyphal formation by the fatty acid signaling molecule trans-2-decenoic acid (SDSF). Chembiochem 11, 1552-1562. doi: 10.1002/cbic.201000086

Wang, L. H., He, Y., Gao, Y., Wu, J. E., Dong, Y. H., He, C., et al. (2004). A bacterial cell-cell communication signal with cross-kingdom structural analogues. Mol. Microbiol. 51, 903-912. doi: 10.1046/j.1365-2958.2003.03883.x

Yang, Y.-X., Xu, Z.-H., Zhang, Y.-Q., Tian, J., Weng, L.-X., and Wang, L.-H. (2012). A new quorum-sensing inhibitor attenuates virulence and decreases antibiotic resistance in Pseudomonas aeruginosa. J. Microbiol. 50, 987-993. doi: 10.1007/s12275-012-2149-7

Conflict of Interest: The authors declare that the research was conducted in the absence of any commercial or financial relationships that could be construed as a potential conflict of interest.

Copyright (C) 2021 Harrison, Awais, Harris, Raji, Hoffman, Baker and Jennings. This is an open-access article distributed under the terms of the Creative Commons Attribution License (CC BY). The use, distribution or reproduction in other forums is permitted, provided the original author(s) and the copyright owner(s) are credited and that the original publication in this journal is cited, in accordance with accepted academic practice. No use, distribution or reproduction is permitted which does not comply with these terms. 